\title{
Considerations for Efficient Airflow Design in Cleanrooms
}

\author{
Tengfang Xu, Ph.D., PE, \\ Lawrence Berkeley National Laboratory
}

\section{Introduction}

A high-performance cleanroom should provide efficient energy performance in addition to effective contamination control. Energy-efficient designs can yield capital and operational cost savings, and can be part of a strategy to improve productivity in the cleanroom industry. Based upon in-situ measurement data from ISO Class 5 cleanrooms, this article discusses key factors affecting cleanroom air system performance and benefits of efficient airflow design in cleanrooms.

Cleanroom HVAC systems used in the semiconductor, pharmaceutical, and healthcare industries are very energy intensive, requiring large volumes of cleaned air to remove or dilute contaminants for satisfactory operations. There is a tendency, however, to design excessive airflow rates into cleanroom HVAC systems, due to factors such as design conservatism, lack of thorough understanding of airflow requirements, concerns about cleanliness reliability, and potential design and operational liabilities.

Energy use of cleanroom environmental systems varies with system type and design, cleanroom functions, and the control of critical parameters such as temperature and humidity. In particular, cleanroom cleanliness requirements specified by cleanliness class ${ }^{1,2}$ have an impact on overall energy use. A previous study ${ }^{3}$ covering Europe and the US reveals annual cleanroom electricity usage for cooling and fan energy varies significantly depending on cleanliness class, and may account for up to three-quarters of total annual operating costs. A study on a semiconductor cleanroom in $\operatorname{Japan}^{4}$ found air delivery systems account for more than $30 \%$ of total power consumption. It is evident that the main factors dictating cleanroom operation energy include airflow rates and HVAC system efficiency.

Improving energy efficiency in cleanrooms may potentially contribute to significant savings in the initial costs of the facilities as well as operation and maintenance costs. For example, energy consumption by a typical chip manufacturer can be cut $40 \%$ or more, and the associated greenhouse emissions even more. ${ }^{5}$ Cleanroom HVAC systems provide huge opportunities for energy savings in the semiconductor industry. ${ }^{6}$

In addition to direct cost reductions in cleanroom investment and operation, energy-efficient designs can reduce maintenance costs, increase power reliability, improve time-to-market in cleanroom production, and improve environmental quality. Companies that use energy efficiency to lower costs and increase productivity can gain a competitive advantage and achieve a higher return on investment. In addition, energy-efficient cleanroom systems conserve energy and natural resources, heightening the company's reputation as an environmentally conscious leader in the community and the industry.

A significant portion of energy use in cleanroom environmental systems is associated with recirculating air systems. We will review and analyze design factors and operational performance of airflow systems in ISO Class 5 cleanrooms. We will also discuss benefits of efficient cleanroom airflow designs in conjunction with effective cleanroom contamination control. We will consider the following common recirculating air system designs: 
fan-tower (FT) with pressurized-plenum

distributed air handler unit (AHU)

fan-filter unit (FFU)

\section{Improving Airflow System Efficiency}

A high-performance cleanroom airflow design should achieve two goals: effective contamination control and efficient airflow delivery. Effective contamination control often requires large quantities of cleaned air via a combination of air recirculation, make-up air, and exhaust parameters. How efficiently the conditioned air is delivered dictates energy needs for operation and may also affect the availability and reliability of the power systems. Major factors determining airflow system efficiency include cleanroom activities (e.g., product, process, cleanliness class), airflow rate, airflow distribution, particle size, particle transport rate, spatial pressure control, and system equipment and components. Analysis of actual cleanroom airflow rates, energy efficiency of AHUs, and other factors affecting airflow performance reveals opportunities for efficient airflow design in cleanrooms.

\section{Cleanroom Airflows-How much is too much?}

It is important to understand the role of air circulation in satisfactory cleanroom performance. Designers and operators often focus on airflow in a given period of time (i.e., airflow rate in terms of air change rate or air velocity). In reality, there is no simple way to relate a cleanliness class level to a specific cleanroom air velocity or air change rate because of complex factors affecting design and operations. It has been common in practice and in ASHRAE and IEST's publications, however, to use cleanroom air velocities and air change rates to quantify airflow requirements.

Three fundamental components characterize cleanroom airflows: 1) the amount of airflow in the cleanroom in a given period of time, 2) the distribution patterns of airflow (velocities and profile) within the cleanroom, and 3) the spatial pressure impact of airflow in and around the cleanroom. Regardless of air distribution, more air alone may not necessarily improve contamination control. To avoid ambiguity, we define cleanroom air velocity as the total circulation airflow rate divided by primary cleanroom floor area (meters per second or feet per minute); and cleanroom air change rate as the total circulation airflow rate divided by primary cleanroom volume (per hour). A prior study by Xu et al. ${ }^{3}$ of relevant publications found various industry recommendations ${ }^{7,8}$ for airflow ranges; however, in-situ measurements showed actual airflow rates (average air velocity or air change rate) were often much lower than the recommended ranges. Recent discussions on an update to IEST-RP-CC-012.1: Considerations for Cleanroom Design ${ }^{9}$ have suggested an air change rate exceeding 200/hr for non-unidirectional airflow and air velocity between $0.20 \mathrm{~m} / \mathrm{s}$ and $0.50 \mathrm{~m} / \mathrm{s}(39 \mathrm{fpm}$ and $98 \mathrm{fpm})$ for unidirectional airflow ISO Class 5 cleanrooms. This recommended range is also included in ISO Standard 14644-4 for ISO Class 5 microelectronic cleanrooms, while a minimal airflow speed of 0.20 $\mathrm{m} / \mathrm{s}$ is specified for unidirectional airflow in ISO Class 5 cleanrooms for processing healthcare products. ${ }^{10}$

Figure 1 compares average air velocities and air change rates for the ISO Class 5 cleanrooms reviewed in this study with recommended ranges that have been or are being developed by IEST. The measured air velocities ranged between approximately $0.10 \mathrm{~m} / \mathrm{s}$ and $0.41 \mathrm{~m} / \mathrm{s}$ (or $20 \mathrm{fpm}$ and $80 \mathrm{fpm}$ ), corresponding to air change rates between $100 / \mathrm{hr}$ and $480 / \mathrm{hr}$. This indicates a large variation in air 
circulation among different systems, depending on design, layout, and cleanroom activities. The finding also shows that providing good airflow distribution, even with an average cleanroom air velocity as low as $0.10 \mathrm{~m} / \mathrm{s}$, can effectively dilute contaminants or disperse particles. The majority of actual airflow rates in the study fell far below the commonly recommended ranges (e.g., $0.46 \mathrm{~m} / \mathrm{s}$, or 90 fpm in ASHRAE; the lower limit of $240 / \mathrm{hr}$ in IEST RP-CC012.1 ${ }^{8}$ ) and the proposed revisions to IEST-RP-CC012.1 (i.e., a lower limit of $200 / \mathrm{hr}$ or $0.20 \mathrm{~m} / \mathrm{s}) .{ }^{9,10}$ Higher airflow rates than needed require greater fan power and associated initial costs. For example, an additional $10 \%$ to $30 \%$ airflow supply would increase fan power by approximately $30 \%$ to $120 \%$. The increased fan power would also in turn increase the cooling load due to extra heat generated from fan motor operation. These results point to opportunities for improving energy efficiency at the design stage by not specifying higher airflow rates than necessary (or sometimes recommended) to achieve high-performance cleanroom operation.

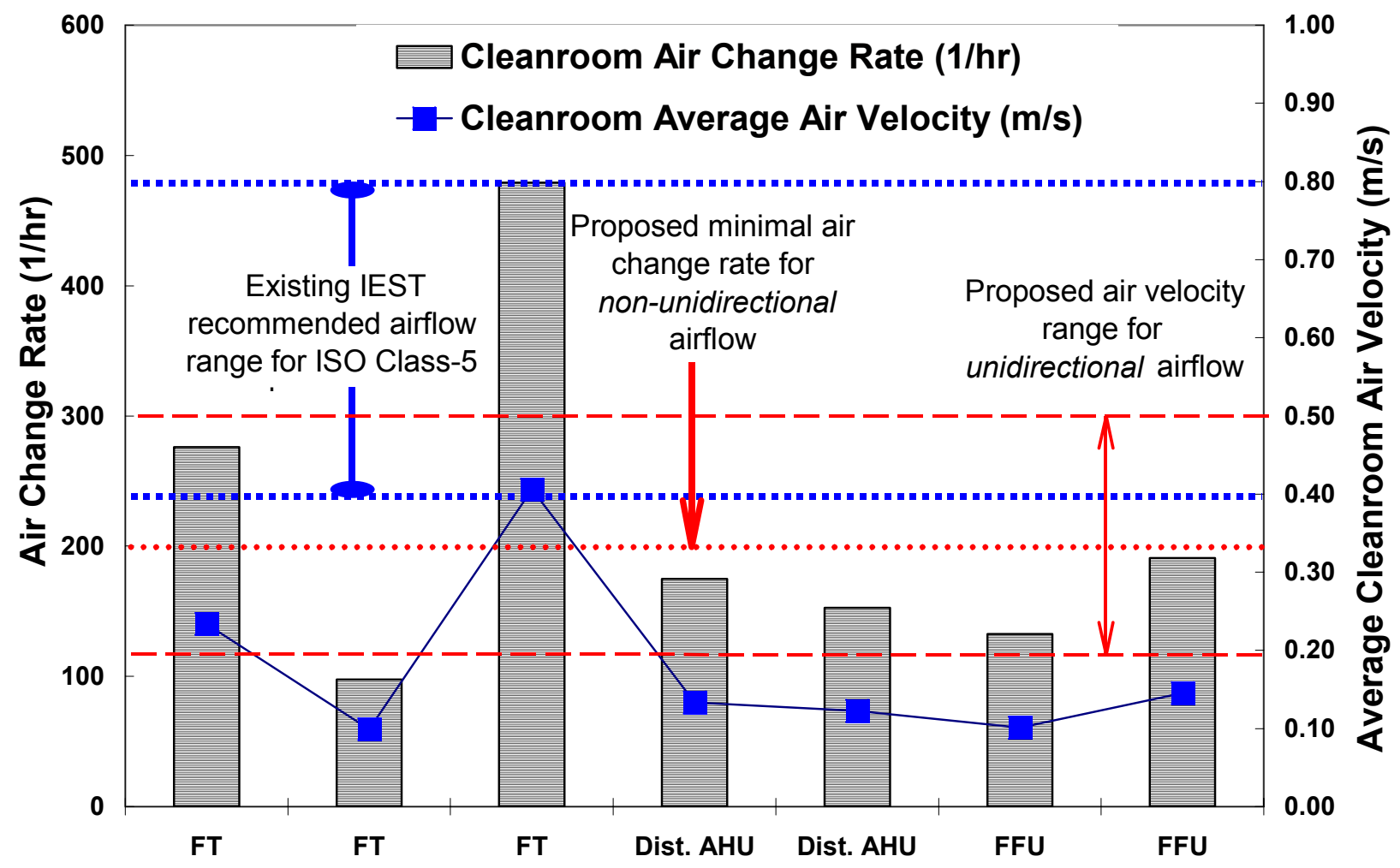

Figure 1. In-situ ISO Class 5 cleanroom air velocities and air change rates.

\section{Energy Efficient Air System Design}

Cleanroom air systems typically combine recirculating air, make-up air, and sometimes exhaust systems. The types of recirculation systems, their sizes, airflow paths, layout, system components, and other design and control details affect overall air system efficiency. Reducing resistance in the air path throughout air handling systems can lower pressure drops, thus requiring less fan power and energy to recirculate air while maintaining effective contamination control. Xu et al. ${ }^{3}$ discovered that energy efficiency of different types of recirculation air systems varied dramatically from cleanroom to 
cleanroom. Fan-tower air systems were generally found to be far more efficient than other types of recirculation air systems (i.e., distributed AHUs and FFUs).

Similarly, configurations of make-up air systems can have a significant impact on overall energy consumption. Depending upon local climatic conditions and specific cleanroom requirements, the treatment of make-up air can be a significant energy user. Make-up air systems, although using significantly less energy than recirculation systems but are usually significantly less efficient than their recirculation counterparts.

\section{Spatial Pressures, Filters, Ceiling Coverage}

While static pressure in cleanroom air systems affects the power required to maintain air movement, the control of spatial pressures in a cleanroom relative to its adjacent facilities is critical to effective contamination control. Accurate pressure control can affect certain cleanroom processes and can act as a barrier to the dispersion of contaminants to the unwanted areas (or as a channel to target areas). For example, a positive cleanroom pressure would be required to keep foreign contaminants from entering the cleanroom; on the other hand, a negative cleanroom pressure would be required to prevent contaminants such as bacteria and hazardous materials inside the cleanroom from escaping through leaks in the cleanroom enclosure. The methods of pressure control are related not only to recirculation airflow, but also to the design details of make-up airflow and exhausts.

Cleanroom air systems recirculate conditioned air through HEPA filters, which have different efficiency levels and effective areas that are less than their actual physical sizes. The ceiling coverage by HEPA filters varies with contamination control requirements, and can range from $25 \%$ to $100 \%$. With lower ceiling coverage, the face velocity of airflow in the filter tends to be higher given the same airflow, resulting in more fan power demand. Filter efficiency, ceiling coverage, and layout should be carefully considered.

\section{Benefits of Efficient Airflow Design}

High-technology manufacturing cleanrooms require extremely reliable high-quality power. These cleanrooms are the most likely to seek competitive energy service deals as electricity markets are deregulated. Some progressive high-technology companies have begun to identify energy efficiency opportunities and service options. Recognizing the high cost of moving air in cleanroom environments, owners and managers of cleanroom facilities should take measures to optimize airflow. There is a tendency to jack up air velocities in the hope of directly lowering particle counts. In some cases, however, higher air velocities have been found to increase particle counts in the test area, while lower velocities decreased the particle counts. ${ }^{11}$

Operation costs may vary significantly depending on cleanroom cleanliness requirement, process, size, system design, and utility rates. To illustrate the operation cost impact of an air circulation system, Figure 2 shows the fan kWh costs for cleanrooms. Based on various system energy efficiencies, the figure uses an assumed airflow of 1,000,000 $\mathrm{m}^{3} / \mathrm{h}$ (about 583,000 cfm), operating 24 hours a day for the whole year (8,760 hours). The US Department of Energy projects average electricity prices at 6.5 to 6.9 cents per kWh between 2002 and 2020. ${ }^{12}$ The two bars compares the kWh costs based on two kWh rates, i.e., 6.5 cents $/ \mathrm{kWh}$ vs. 6.9 cents $/ \mathrm{kWh}$, for each Class 5 cleanroom with the measured efficiency $(\mathrm{cfm} / \mathrm{kW})$ and with a hypothetical recirculation rate of $1,000,000 \mathrm{~m}^{3} / \mathrm{h}$ (or $\left.583,000 \mathrm{cfm}\right)$. This cost estimate excludes any energy demand charges. On average the annual fan $\mathrm{kWh}$ costs alone for the 
cleanrooms with less efficient AHUs (i.e., distributed AHUs and FFU) can range from $\$ 150,000$ to more than $\$ 300,000$. Significant cost savings in cleanroom operations could be realized by increasing the efficiency for such air systems.

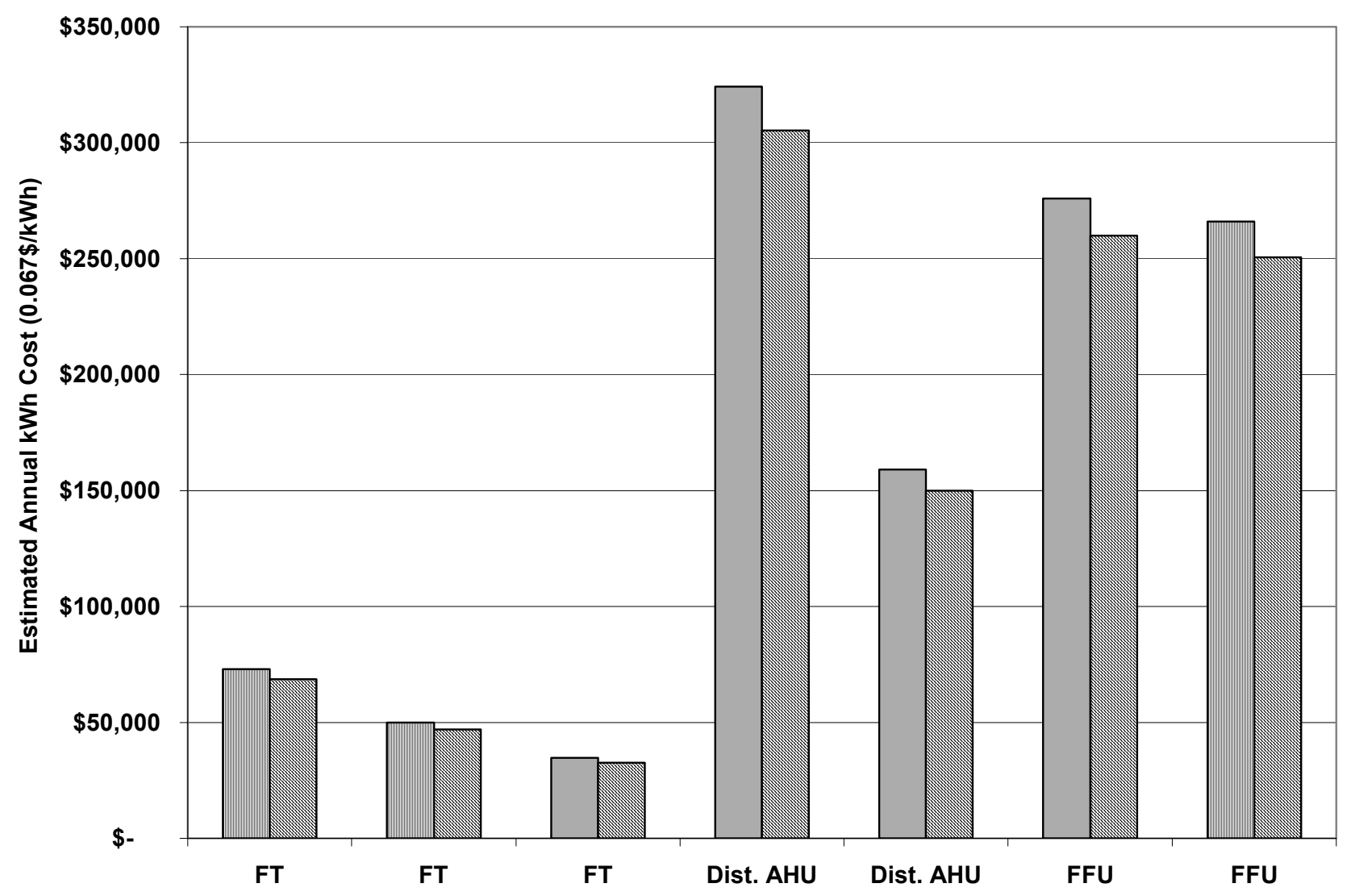

Figure 2. Projection of annual fan $\mathrm{kWh}$ cost (fans for air circulation) between year 2002 to 2020 for an $1,000,000 \mathrm{~m}^{3} / \mathrm{h}($ or $583,000 \mathrm{cfm})$ Class 5 cleanroom

\section{Conclusions and Recommendations}

Cleanroom airflow design and operation can have a long-term impact on energy usage. Design airflows and loads have a significant effect on the initial costs of air systems as well as subsequent energy and operation costs. Based on the review of in-situ measurements and an array of design factors, this study found efficient, optimally sized airflow systems can, in practice, reduce initial costs and help cleanrooms achieve high performance that can benefit productivity.

During the planning and design phases, designers and owners of cleanrooms should consider energyefficient design as a strategy to achieve cost savings. It is important not to specify excessively higher 
airflow supply than is needed for a specific process. When selecting an energy-efficient air system, designers should evaluate system design parameters using an integrated approach that considers initial costs, operating costs, process loads, cleanroom performance requirements, appropriate airflow rates, necessary space and adjacencies, and applicable types of air delivery systems that use energy-efficient components. Implementing this energy-saving, environmentally conscious approach will also strengthen employee and public perceptions of the company as an industry leader.

\section{Acknowledgments}

This article is based on a technical paper presented at ESTECH 2003. ${ }^{13}$ The work was supported by the Assistant Secretary for Energy Efficiency and Renewable Energy, Office of Building Technologies Program of the US Department of Energy under Contract No. DE-AC03-76SF00098.

\section{About the author}

Dr. Tengfang $\mathrm{Xu}$ is a project manager and researcher in the Environmental Energy Technologies Division, Lawrence Berkeley National Laboratory (LBNL), Berkeley, California. He obtained his B.S. and M.S. degrees from Tsinghua University, Beijing, and a Ph.D. from the UC-Berkeley. He is a licensed Professional Engineer (P.E.) in California with 16 years of research and consulting experience in indoor environment, energy, human factors, and building systems. A senior member of IEST, Xu is a Technical Editor for the Journal of the IEST.

\section{References}

1. International Organization for Standardization (ISO). 1999. ISO/DIS 14644-1 Cleanrooms and associated controlled environments. Part 1: Classification of air cleanliness. The Institute of Environmental Sciences and Technology (IEST), 5005 Newport Drive, Suite 506, Rolling Meadows, IL 60008-3841, USA.

2. International Organization for Standardization (ISO). 2000. ISO/DIS 14644-2 Cleanrooms and associated controlled environments. Part 2: Testing and monitoring to prove continued compliance to ISO/DIS 14644-1. The Institute of Environmental Sciences and Technology (IEST), 5005 Newport Drive, Suite 506, Rolling Meadows, IL 60008-3841, USA.

3. Xu, T. 2003. Performance Evaluation of Cleanroom Environmental Systems. . Journal of the IEST, 2003 Edition, Vol. 46:66-73. Institute of Environmental Sciences and Technology (IEST), 5005 Newport Drive, Suite 506, Rolling Meadows, IL 60008-3841, USA.

4. Matsuki, M., and N. Tanaka. 1998. Energy Saving System for Air Conditioning of Clean Room for Semiconductor Factory (Estimation of FMU System). Oki Technical Review Vol. 63: Special Issue on Global Environment: UDC [628.83: 621.63-831]. Available from http://www.oki.com/en/otr/downloads/otr-160-12.pdf, the page last accessed on July 27, 2004.

5. Center for Energy \& Climate Solutions (CECS). Cool High-Tech \& Cleaner Clean Rooms: New Economy Manufacturers Find Big Energy Savings. http://www.cool-companies.org/proven/tech.cfm. The page last accessed on July 27, 2004. CECS: A Division of the Global Environment \& Technology Foundation, http://www.getf.org, 7010 Little River Turnpike, Suite 460, Annandale, VA 22003.

6. Lee, A.H, F. Karman. 2003. Energy Conservation Measures for Industrial Facilities. HPAC Engineering, July 2003: 45-49. 1300 E. 9th St. Cleveland, OH: www.HPAC.com. 
7. ASHRAE. 1995. ASHRAE Handbook: HVAC Applications. American Society of Heating, Refrigerating, and Air Conditioning Engineers, Inc., Atlanta, GA, USA.

8. The Institute of Environmental Sciences and Technology (IEST). 1998. Considerations in Cleanroom Design. IEST Recommended Practice 012.1 (IEST-RP-CC012.1). The Institute of Environmental Sciences and Technology, 5005 Newport Drive, Suite 506, Rolling Meadows, IL 60008-3841, USA.

9. Fitzpatrick, M, and K. Goldstein. 2002. Cleanroom Airflows Part II: The Messy Details.

CleanRooms. PennWell Corporation. Available from http://cr.pennnet.com/, the page last accessed on July 27, 2004.

10. International Organization for Standardization (ISO). 2001. ISO 14644-4: Cleanrooms and Associated Controlled Environments. Part 4: Design, Construction and Start-up. The Institute of Environmental Sciences and Technology (IEST), 5005 Newport Drive, Suite 506, Rolling Meadows, IL 60008-3841, USA.

11. DeSorbo, M. 2000. Decreased Air Velocity Cuts Costs. CleanRooms. PennWell Corporation. Available from http://cr.pennnet.com/, the page last accessed on July 27, 2004.

12. Energy Information Administration. 2002. Overview of Annual Energy Outlook 2002 (AEO 2002) with Projections to 2020. Department of Energy. Available from http://www.eia.doe.gov/oiaf/aeo/index.html, the page last modified on November 30, 2002.

13. Xu, T. 2003. Efficient Airflow Design for Cleanrooms Improves Business Bottom Lines. Proceedings of The 49th Annual Technical Meeting, Phoenix, AZ, USA. April: Institute of Environmental Sciences and Technology (IEST). 